JELTL (Journal of English Language Teaching and Linguistics) e-ISSN: 2502-6062, p-ISSN: 2503-1848

2019, Vol. 4(3)

www.jeltl.org

\title{
Level of Knowledge Awareness and Use of Planning as Writing Strategy by EFL International Students in UUM English Intensive Course
}

\author{
Mohammed Ahmad Ado ${ }^{1,2 *}$ \\ 1.Bauchi State University, Gadau, Nigeria \\ 2.Universiti Utara Malaysia \\ e-mail: ado.ahmedmohammed@yahoo.com \\ Mohammad Othman Ahmad Alsheyab \\ Universiti Utara Malaysia \\ e-mail:Msheyab@gmail.com
}

\begin{abstract}
Malaysian English Language Curriculum makes it compulsory for every newly intake student to master and pass the English Writing Tasks (EWT) as among the basic skills in the language learning processes. However, most of the English Foreign Language (EFL) international students face difficulties with the EWT during the English Intensive Course (EIC) leading to consistent mass failures. The possible reasons of these failures could be due to the neglect of the writing strategies. Hence, the central focus of this paper is to identify and determine the EFL international students' level of awareness and the use of planning as writing strategy before writing English essays. To this end, convenient purposive sampling strategy was used where 50 EFL (postgraduate and undergraduate) international students drawn from Universiti Utara Malaysian EIC program were selected and administered Writing Strategy Questionnaires (WSQ). The participants hailed from various countries who used and learned English as a foreign language, namely; Jordan, Iraq, Saudi Arabia, Libya, Palestine among others. The data were analyzed using SPSS. The findings revealed proportionate disparity between the EFL students that use planning strategy before starting writing English essays (usually true $=28 \%$ ) with those that do not (usually not true $=28 \%$ ). In terms of Revising Requirement for writing process before one start writing an essay in English, the findings revealed validity (40\%) of participants' responses at $82 \%$ cumulative.
\end{abstract}


Mohammed Ahmad Ado \& Mohammad Othman Ahmad Alsheyab

This is followed by "somewhat true" responses at $24 \%$ and $42 \%$ cumulative. These imply the EFL international students' reasonable use of planning and having knowledge awareness of writing strategy.

Keywords: English as foreign language, knowledge awareness, writing strategy

\section{INTRODUCTION}

English language is a lingua franca across the globe and has become the first, second or even foreign language of several countries (Crystal, 2003; Rababah \& Melhem, 2015). As a common language, for decades English has cut across international communication by people of different classes, cultures, races, and is mostly used as language of knowledge in various field including human innovations in research, science, medicine, literature among others (Crystal, 2003; Rababah \& Melhem, 2015). Ibnian (2011) further maintained that English language skills play prime role in education especially in guiding students in enhancing their cognitive faculties and creative skills through the use of language processes in relation to comments, predictions, recalls, application, comprehension, evaluation among others. To this effect, scholars such as Bjork \& Raisanen (1997) were of the opinion that writing skill is rated as among the skills of thoughts basically responsible for creative development as well as extension for learning in all disciplines.

In fact, writing as an outstanding and productive skill is mostly considered as challenging, difficult and frustrating aspect in teaching to both English as Second Language (ESL) and English as Foreign Language (EFL) students (Al-Buainain, 2011; Maarof \& Murat, 2013). According to Maarof \& Murat (2013), most students find it challenging in writing be it as ESL or EFL. This could be the reason Nunan (1992) held the opinion that the most painstaking task to do in language learning is to produce an articulated, fluent as well as extended piece of writing which is even more challenging for second language learners. Of course, writing being a process to which writers normally identify and employ in disseminating their ideas with meaningful information, is obviously problem solving activity rather than a simple act of communication (Maarof \& Murat, 2013). This confirmed Hyland's (2008) assertion that with writing task strategies; writers have the liberty of seeking solution to a number of issues.

In this trend, several scholars (e.g., Ridhuan \& Abdullah, 2009; Ou, 2013; Lee et al., 2016) concurred that writing is a basic skill that required mastering by students from every capacity and irrespective of their nationalities. In line with this, Ou (2013) put it that writing is basically among the essential tools employed in learning and evaluation in tertiary institutions across the United State. Due to the use of writing as part of the major tools of assessing student's learning performances, quite a number of international students whose first language is not English are faced with serious tremor in trying to accomplish several writing tasks in English which is their second or foreign language Ou (2013). Another devastating problem $\mathrm{Ou}$ (2013) pointed out is that, despite this difficulty, the international students must acquire the ability and skill of producing well-written English essay/texts 
before obtaining consideration for graduation. This kind of trend is no different with international students of other higher institutions of learning across the world (UUM inclusive) who fall within the non-native speakers of English. This clearly established that international students, especially the EFL are quite aware of the significance attached with writing strategies within the academic terrain as part of their major academic concerns.

Therefore, despite the complexities attached with the writing strategies and processes, yet they are still considered significant to learn or study by students especially the international ones whose first language is not English to enable successful write-ups. In conformity with this, Ridhuan \& Abdullah (2009) highlights that the use of strategies in the writing process is vital to successful writing, hence, students required to be encouraged to use various ways of these strategies in order to improve their writing qualities (Lee et al., 2016). Equally, Ridhuan \& Abdullah (2009) expounded that the kinds and number of strategies employed, including the observation of regulations operative for generating ideas as well as the revision of what the writer have written determine the quality of the written texts/essays.

However, little attention is paid on this aspect, especially towards the international students who use English as a foreign language. Therefore, the current paper intends to identify the level of knowledge awareness and the use of planning writing strategy of the EFL International students in UUM English Intensive Course before writing English Essays. The rationale of choosing these International EFL students is that, it is mandatory for them to undergo and pass the English Intensive Course before commencing with their regular programs (both undergraduate and postgraduate) in UUM.

Universiti Utara Malaysia organised English Intensive Course for international students whose English is used as foreign language. The main purpose is to upgrade their skills, knowledge and abilities to improve their language performance in all the four skills of speaking, listening, reading and most especially the writing skills. The students can improve their writing performance only if they employ the learn skills at their academic activities. If the students fail to employ the learn skills at their academic activities, all the effort of the language instructors will be considered a waste. Hence, instructors normally put their best in training the EFL students during English Intensive Course to utilise the learned skills (especially writing) in their academic activities.

\section{LITERATURE REVIEW}

Review of relevant literature revealed that writing strategies has received quite a lot of attention recently. In this instance, Raoofi et al. (2014) focused on the qualitative approach on the second language writing strategies used by tertiary students. Mistar, Zuhairi, \& Parlindungan (2014) on their parts, studied the learning strategies of writing skill as employed by senior the students of higher institutions at Indonesia and measured the level of use along with the differences accrued using the writing strategies. In the study of Zhang (2016), the focus was more on student engagement with computer-generated feedback, while Sanavi \& Nemati (2014)) attention was on how the International English Language Testing System (IELTS-) contenders could be assisted to perform better in the writing component of the test based on the feedback obtained. Another study was reviewed on the correlation between the writing tasks, learners' learning style preference, and writing strategy use by 
Alkubaidi (2014). The literature also shows that Alkubaidi (2014) shares similarity with the current paper in terms of the instrument used as both adapted Petric \& Czarl (2003) writing strategy questionnaire. However, the current paper used multinational participants while Alkubaidi (2014) strictly used Saudi English Major University Students. similar to Alkubaidi (2014), Bai, Hu, \& Gu (2014) also examined the relationship between the use of writing strategies and English proficiency however the study was directed on the Singapore primary schools. In contrast, the study of Al Seyabi \& Tuzlukova (2014) was on the writing problems and strategies with specific to university context (Omani schools).

On a similar trend, Cole \& Feng (2015) investigated the effective strategies meant for improving writing skills of elementary English language learners. The work of Odena \& Burgess (2017) is a bit difference compared with Cole \& Feng (2015) as they concentrated on the experiences and writing strategies used by the doctoral students and graduate while learning thesis writing processes. On the contrary, Junqueira \& Payant (2015) conducted a case study investigation of teacher feedback beliefs and practices of a pre-service L2 writing teacher focusing on one academic semester only. In similar vein, Zhao (2014) paid more attention on the investigation of teacher-supported peer assessment of EFL writings. However, the study of Liu (2015) was on the English writing strategies but the focus was mainly on the Chinese senior higher school students. The objective of Liu (2015) was on the exploration of the types of writing strategies adopted by the students and the consistency of use. Liu (2015) also concentrated on the impact of gender difference and proficiency with regards to the $\mathrm{L} 2$ writings.

The following year, MacLeod (2016) dwelled on the experiences of Junior-Level English Language Learners in Southwestern Ontario. In the course, the transcripts derived from 400 pages of the students' academic writing development was thematised through Nvivo software. The recent study of Teng \& Zhang (2018), on the other hand, was geared towards the examination of the effects of motivational regulation strategies on writing performance, specifically in English as a second language. To that effect, the researchers employed the responses of undergraduate students from China. In addition, the review of related studies presents the work of Nemati et al. (2017) who in their attempt investigated the learners' language perceptions, beliefs, and preferences with regards to the teachers' feedback practices within Iranian classrooms. Moreso, the review of related literature enable the researcher come across the work of Cutumisu \& Schwartz (2018) who examined the impact of critical feedback choice on students' revision, performance, learning and memory. To achieve their research objective, Cutumisu \& Schwartz (2018) utilised six Grade 8 middle-school students through digital assessment game (posterlet) revealing positivity is associated with performance and negativity is associated with learning when receiving feedbacks. Manchón (2018) offers a survey on the nature of L2 writing strategies and a prospective discussion of potential theoretical and pedagogical relevant lines of inquiry towards future research agendas. Having reviewed these tremendous studies, yet the researcher realized that there is paucity of study that focused on the knowledge awareness of planning writing strategies, especially by the EFL international students in diaspora at the postgraduate level. Hence, given the motivation for the conduct of the present paper. Therefore, in the attempt to identify and determine the level of knowledge awareness and the 
planning used as writing strategy by the EFL international students in UUM English Intensive Course, this paper adapted the planning strategies as the IV and the students' writing performance as the DV. This in turn indicate that writing performance depends on planning strategy its knowledge awareness (Flower \& Hayes, 1980; 1981).

\section{RESEARCH METHODS}

This paper is quantitative in nature and focuses on descriptive research. Accordingly, with descriptive approach the researcher was able to describe the characteristics of certain variables. In this respect, the Independent variable is planning strategies affecting the students writing performance as dependent variable. The major focus of this paper was basically on the interpretation and descriptions in accordance with the quantitative findings about the students' writing problems.

This paper employed purposive (convenient) sampling strategy in selecting the UUM EFL international students. Purposive sampling is part of non-probability sample that conforms to certain criteria and involved two major types: judgement sampling and quota sampling (Bhatti \& Sundram, 2015). In this paper, the EFL students were conveniently sampled based on their relevancy to the targeted objective.

Therefore, the main concern of this paper is to gain much understanding of the EFL international students' awareness and the use of planning writing strategies before writing English Essay as part of their academic activities. These students have two major features significant to this paper including being non-native speakers of English and their current situation as undergraduate and postgraduate students in another country other than theirs (i.e., Malaysia).

Moreover, ESL/ EFL international are normally expose to writing assignments in English with lesser consideration in their respective countries, while the Malaysian higher institution made it compulsory for these students to produce and pass quite a large number of rigorous writing activities. Until then they could not allow to obtain placement into the mainstream of the academic system. For this paper, 50 EFL international students including both male and female were selected and administered with WSQ. These students were drawn from UUM English Intensive Course program during 2018/2019 session.

This paper adapted Petric \& Czarl (2003) Writing Strategy Questionnaire (WSQ) as instrument for data collection. Petric \& Czarl (2003) originally designed WSQ with 38-items 5 point Likert scale questionnaire for measuring the writing strategies and published as Validating a Writing Strategy Questionnaire. However, in the attempt to achieve the objective of this paper the WSQ is modified and administered to the respondents.

In fact, there were 70 participants who participated in the data collection, however due to the issue of outliers found by the researcher, only 50 WSQ were successfully received and analyzed. This has become viable due to the absentees of some students during the conduct of the collection of the data. Hence the researcher was able to take note of such kind of eventualities and other unforeseen abnormalities that arises including the existence of the outliers and made necessary adjustment and elimination of the unwanted ones.

In line with Cresswell (2005), Bhatti \& Sundram (2015) and others, the researcher had imported the study data been derived from research WSQ into the Microsoft excel 2010 software and formatted the background information. Afterwards, the researcher had 


\section{Mohammed Ahmad Ado \& Mohammad Othman Ahmad Alsheyab}

calculated the descriptive statistics of the demographics and the writing experiences as well as the WSQ in the attempt to view the responses of the questions therein. Subsequently the main part of the data was also imported into the SPSS software. With this software, the researcher was able to calculate and analyse the frequency, percentages as well as the means for the students' demographics and their level of knowledge awareness and experiences of writing strategies.

\section{FINDINGS}

\subsection{Results of the Analysis of the Students' Responses on Planning Strategies}

The first part of the WSQ that has been analyzed contained eight sub-questions regarding the planning strategies before the student start writing essay in English, namely: 1. I make a timetable before for the writing process, 2. Before I start writing I revise the requirements, $\mathbf{3}$. I look at a model written by a native speaker or more proficient writer, $\mathbf{4}$. I start writing without having a written or mental plan, 5. I think about what I want to write and have a plan in my mind, but not on paper, 6. I note down words and short notes related to the topic, 7. I write an outline of my paper and 8. I write notes or an outline in my native language.

\subsection{Frequency Distribution of Students' responses over making timetable for the writing process before start writing an Essay in English}

Analysis of the WSQ data of this study shows that EFL international students had responded remarkably. The findings revealed that majority of the students had proportionate responses in terms of frequency and percentage of making timetable for the writing process as part of planning strategy use before starting to write essay in English.

Table 4.1: Frequency Distribution of Students' responses toward making timetable for writing process before start writing an essay in English

\begin{tabular}{llcccc}
\hline \multirow{3}{*}{ Valid } & Frequency & Percent & Valid Percent & Cumulative Percent \\
& Never true & 5 & 10.0 & 10.0 & 10.0 \\
& Usually not true & 14 & 28.0 & 28.0 & 38.0 \\
& Somewhat true & 11 & 22.0 & 22.0 & 60.0 \\
& Usually true & 14 & 28.0 & 28.0 & 88.0 \\
& Always true & 6 & 12.0 & 12.0 & 100.0 \\
Total & $\mathbf{5 0}$ & $\mathbf{1 0 0 . 0}$ & $\mathbf{1 0 0 . 0}$ & \\
\hline
\end{tabular}

From the analyzed data, the findings show that 50 participants had responded. Table 4.1 displays 14 students whose responses claim that they do not often make a timetable before they start writing an essay in English (usually not true) which is at proportionate level with those (i.e., 14 students' responses) who had partial agreement (usually true) that they sometimes make timetable before they start writing an essay in English. By implication the findings revealed that there is a corresponding frequency (14) and percentage between responses of "usually not true" and "usually true" by the participants as each has $28 \%$ awareness and use of timetable before writing an essay. However, the cumulative percentage 
of these two classes of participants revealed some kind of disparity as those with (usually not true) has $38 \%$ which is less that those with (usually true) responses as having $88 \%$.

On the other hand, the participants who responded with "never true" about the awareness and use of timetable before writing an essay in English had the least frequency with only 5 responses at $10 \%$ including the cumulative average, while those with "always true" had 6 responses at $100 \%$ cumulative at $12 \%$ validation. In addition, the students with "somewhat true" responses may be viewed as those with more than average awareness and use of timetable before start writing an essay in English for having 11 respondents' frequency at $22 \%$ and $60 \%$ cumulative.

\subsection{Frequency Distribution of Students' responses over Revising the Requirement for the writing process before start writing an Essay in English}

The frequency distribution of the EFL students' responses over revising the requirement for the writing process before start writing an assay in English as revealed in Table 4.2. The result shows that most students have partial agreement and awareness of revision as requirement compared with other four items used in the WSQ of planning strategy.

Based on the result reflected in table 4.2 below, 20 participants agreed that it is true that they sometimes do revise the requirement of the writing process before they start writing an essay in English by having $40 \%$ of validity of their responses at $82 \%$ cumulative. This is followed by 12 respondents who have "somewhat true" responses at $24 \%$ and $42 \%$ cumulative agreement of being aware of the writing process as well as using the revising requirement before starting an essay in English.

Table 4.2: Frequency Distribution of Students' responses toward Revising Requirement for writing process before start writing an essay in English

\begin{tabular}{llcccc}
\hline \multirow{3}{*}{ Valid } & Frequency & Percent & Valid Percent & Cumulative Percent \\
& Never true & 1 & 2.0 & 2.0 & 2.0 \\
& Usually not true & 8 & 16.0 & 16.0 & 18.0 \\
& Somewhat true & 12 & 24.0 & 24.0 & 42.0 \\
& Usually true & 20 & 40.0 & 40.0 & 82.0 \\
Always true & 9 & 18.0 & 18.0 & 100.0 \\
& Total & $\mathbf{5 0}$ & $\mathbf{1 0 0 . 0}$ & $\mathbf{1 0 0 . 0}$ & \\
\hline
\end{tabular}

On the other hand, the frequency of responses of those respondents with "Always true" and "usually not true" is slightly similar as the former has nine frequency level of agreement at $18 \%$, while the latter has eight frequency levels of agreement of use and awareness of revising requirement before start writing an essay in English. But with high differences in terms of cumulative for the former has $100 \%$ in contrast with the latter with only $42 \%$ cumulative. Meanwhile the result as seen in the table indicated that only one participant being the least who disagreed and claim of "never true" of using revision of the requirement of writing process before starting an essay in English as having 2\% for both valid and cumulative percentages. By implication there is a reasonable use and awareness of revising requirement of writing process by EFL international students before they start writing an essay in English.

JELTL (Journal of English Language Teaching and Linguistics), 4(3), 2019 


\subsection{Frequency Distribution of Students' responses over looking at a model written by a native speaker or more proficient writer before start writing an Essay in English}

Based on the analysis of the WSQ data of this study, the findings revealed a considerable use of model written by naïve speakers or more proficient writers by EFL international students before they start writing an essay in English during English intensive course. The frequency distribution of the EFL students' responses over the use of the model written by native speakers of English or more proficient writers is presented in Table 4.3 below:

Table 4.3: Frequency Distribution of Students' responses over looking at a model written by a native speaker or more proficient writer before start writing an essay in English

\begin{tabular}{llcccc}
\hline \multirow{3}{*}{ Valid } & Frequency & Percent & Valid Percent & Cumulative Percent \\
& Never true & 4 & 8.0 & 8.0 & 8.0 \\
& Usually not true & 10 & 20.0 & 20.0 & 28.0 \\
& Somewhat true & 11 & 22.0 & 22.0 & 50.0 \\
& Usually true & 15 & 30.0 & 30.0 & 80.0 \\
Always true & 10 & 20.0 & 20.0 & 100.0 \\
\hline
\end{tabular}

In accordance with the result shown in Table 4.3 above, most students (15 of 50 participants) expressed partial agreement (i.e., usually true) of the usage and awareness of looking at a model written by a native speaker or more proficient writer before starting writing an essay in English as compared with other four items used in the WSQ of planning strategy. The frequency of these 15 respondents had reflected the highest level of knowledge awareness and usage with $30 \%$ validation and $80 \%$ cumulative percentage. This is followed by eleven responses of "somewhat true" at $22 \%$ of validation and $50 \%$ cumulative of usage before starting writing an essay in English.

On the other hand, the frequency distribution of 50 students who responded in this study, the result from table 4.3 indicates that there is a corresponding result of frequency of responses and percentage of usage on "usually not true" and "usually true" as both have 10 respondents each with equal valid percentage (20\%). however, differs in terms of cumulative for those who partially disagree (usually not true) in their responses had only $28 \%$ cumulative which is less compared with those that responded with partial agreement "usually true" by having the cumulative of $100 \%$ significance. Similar with other previous items of planning strategy (i.e., timetable and revising requirement) being used by EFL students before they start writing an essay in English, looking at a model written by a native speaker or more proficient writer is also used the least compared with other items under this. As only four respondents had responded that they never use this strategy (never true) at $8 \%$ and $8 \%$ cumulative respectively.

4.5 Frequency Distribution of Students' responses of writing without having a written or mental plan of writing process before start writing an Essay in English 
Level of Knowledge Awareness and Use of Planning as Writing Strategy

Table 4.4: Frequency Distribution of Students' responses of writing without having a written or mental plan of writing process before start writing an essay in English

\begin{tabular}{llcccc}
\hline \multirow{4}{*}{ Valid } & Frequency & Percent & Valid Percent & Cumulative Percent \\
& Never true & 10 & 20.0 & 20.0 & 20.0 \\
& Usually not true & 14 & 28.0 & 28.0 & 48.0 \\
& Somewhat true & 14 & 28.0 & 28.0 & 76.0 \\
& Usually true & 9 & 18.0 & 18.0 & 94.0 \\
Always true & 3 & 6.0 & 6.0 & 100.0 \\
Total & $\mathbf{5 0}$ & $\mathbf{1 0 0 . 0}$ & $\mathbf{1 0 0 . 0}$ & \\
\hline
\end{tabular}

The responses of the 50 EFL students been used as participants revealed a significant and positive result as shown in table 4.4 above. The result indicated in table 4.4 shows that there is a proportionate frequency of responses and percentage between respondents who partially disagree, that is, "usually not true" and those who claim of being "somewhat true" as both has 14 number of respondents and responses at $28 \%$ each in terms of writing without having a written or mental plan before they start writing an essay in English. Although in terms of cumulative percentage, they differ as the former has $48 \%$ which is far less than the latter as it has $76 \%$ of cumulative probable assurance of being aware and use of this strategy. This is followed by "never true" with ten respondents' frequency at $20 \%$ validation and cumulative respectively.

On the other hand, the result has indicated that there is an average frequency of responses by the 9 EFL international students as having $18 \%$ of "usually true" at $94 \%$ cumulative, while total agreement (always true) with this strategy, that is, "start writing without having a written or mental plan" is the least of all by having only 3 respondents at $6 \%$ and $100 \%$ cumulative.

These findings suggest that there is no conclusive position and opinion as to whether or not that the EFL international students do start writing without having a written or mental plan. The obvious reason is that by cumulative percentage if one combines those with "never true" responses with "usually not true" (i.e., $20 \%$ plus $48 \%=68 \%$ ) the result is far less than those with "somewhat true", "usually true" and "always true" $(76 \%+94 \%+100 \%=270 \%)$.

\subsection{Frequency Distribution of Students' responses of Student's thought, want and plan in mind on what to write before start writing an Essay in English}

The analysis of the WSQ data of this study revealed that 50 EFL international students had responded about their conscious knowledge, awareness and use of their thought, want and plan in mind on what to write before start writing an essay in English during UUM English intensive course as shown in table 4.5 below.

Table 4.5: Frequency Distribution of Students' responses of Student's thought, want and plan in mind on what to write before start writing an essay in English

\begin{tabular}{llcccc}
\hline \multirow{4}{*}{ Valid } & Frequency & Percent & Valid Percent & Cumulative Percent \\
& Never true & 2 & 4.0 & 4.0 & 4.0 \\
& Usually not true & 7 & 14.0 & 14.0 & 18.0 \\
& Somewhat true & 14 & 28.0 & 28.0 & 46.0 \\
Usually true & 13 & 26.0 & 26.0 & 72.0 \\
Always true & 14 & 28.0 & 28.0 & 100.0 \\
Total & $\mathbf{5 0}$ & $\mathbf{1 0 0 . 0}$ & $\mathbf{1 0 0 . 0}$ & \\
\hline
\end{tabular}

JELTL (Journal of English Language Teaching and Linguistics), 4(3), 2019 
From the result of the responses indicated in table 4.5, it is clear that majority of the respondents have agreed of having the thought, want and plan in mind on what to write before start writing an essay in English. For instance; 14 respondents have $28 \%$ of responses on the use of knowledge awareness of this strategy to certain extent (somewhat true), equally another 14 respondents have corresponding percentage (i.e., 28\%) of assurance which is "always true", although there is a contrasting cumulative percentage as those with "somewhat true" have less at $46 \%$ compared to those with "always true" responses being at $100 \%$ degree of agreement. This is followed by the "usually true", where 13 respondents had $26 \%$ of partial agreement of having the thought, want and plan in mind on what to write before start writing an essay in English at $72 \%$ cumulative.

On the contrary, 7 respondents had $14 \%$ responses of skeptical disagreement (usually not true) of having the thought, want and plan in mind on what to write before start writing an essay in English at 18\% cumulative average. On the other hand, the result revealed only 2 respondents who claimed of complete denial or disagreement (i.e., never true) of having the thought, want and plan in mind on what to write before start writing an essay in English at $4 \%$ each for validation and cumulative percentage.

\subsection{Frequency Distribution of Students' responses of Student's Conscious use of noting down of words and short notes related to topic before start writing an Essay in English}

The analysis of the WSQ data of this study also revealed that $50 \mathrm{EFL}$ international students had responded about their conscious use of noting down words and short notes related to topic before start writing an essay in English during UUM English intensive course as shown in Table 4.6 below.

Table 4.6: Frequency Distribution of Students' responses of Student's Conscious use of noting down of words and short notes related to topic before start writing an essay in English

\begin{tabular}{llcccc}
\hline \multirow{3}{*}{ Valid } & Frequency & Percent & Valid Percent & Cumulative Percent \\
& Never true & 1 & 2.0 & 2.0 & 2.0 \\
& Usually not true & 9 & 18.0 & 18.0 & 20.0 \\
& Somewhat true & 8 & 16.0 & 16.0 & 36.0 \\
& Usually true & 27 & 54.0 & 54.0 & 90.0 \\
Always true & 5 & 10.0 & 10.0 & 100.0 \\
Total & $\mathbf{5 0}$ & $\mathbf{1 0 0 . 0}$ & $\mathbf{1 0 0 . 0}$ & \\
\hline
\end{tabular}

Base on the statistical description displays in table 4.6 above, the result shows that majority of the EFL international students have conscious use of noting down words and short notes related to topic before start writing an essay in English during UUM English intensive course. This is clearly shows as 27 respondents being more than half of the total number of who responded in the study used 54\% of "usually true" as their answer with $90 \%$ cumulative percentage.

On the other hand, as indicated in the table 4.6, there is a slight similarity of percentage between responses of those who use "usually not true" with the ones that use "somewhat true" as the former have 9 respondents with $18 \%$ at $20 \%$ cumulative, while the latter had 8 
respondents with $16 \%$ at $36 \%$ cumulative. By implication, there are student on average that feel uncertain about the conscious use of noting down words and short notes related to topic before start writing an essay in English during UUM English intensive course, although the result shows that there are students as few as 5 who completely agreed (always true) that the use this strategy by having $10 \%$ with $100 \%$ cumulative percentage. As far as this strategy, it was only one respondent with $2 \%$ both for valid and cumulative percentage that claimed of not noting down words and short notes related to topic before start writing an essay in English during UUM English intensive course which is the least of all the items used.

\subsection{Frequency Distribution of Students' responses of Student's Conscious use of writing an outline on paper before start writing an Essay in English}

Based on WSQ data of this study the analysis also revealed that 50 EFL international students had responded about their conscious use of writing an outline in their paper before start writing an essay in English during UUM English intensive course and this is shown in table 4.7 below.

The statistical representation of the frequency distribution of the students' responses as indicated in table 4.7 below, the frequency of the respondents who agreed that they write an outline in their paper before start writing an essay in English during UUM English intensive course are far higher than any other item. In this sense, 19 respondents agreed with $38 \%$ that it is "usually true" that they write and use an outline on paper at $84 \%$ cumulative average. Similarly, 10 respondents had agreement of the use of an outline on paper; however, the answers were "somewhat true" responses at $20 \%$ with $46 \%$ cumulative average.

Table 4.7: Frequency Distribution of Students' responses of Conscious use of writing an outline on paper before start writing an essay in English

\begin{tabular}{llcccc}
\hline \multirow{3}{*}{ Valid } & Frequency & Percent & Valid Percent & Cumulative Percent \\
& Never true & 5 & 10.0 & 10.0 & 10.0 \\
& Usually not true & 8 & 16.0 & 16.0 & 26.0 \\
& Somewhat true & 10 & 20.0 & 20.0 & 46.0 \\
& Usually true & 19 & 38.0 & 38.0 & 84.0 \\
Always true & 8 & 16.0 & 16.0 & 100.0 \\
\hline
\end{tabular}

On the contrary, there is a proportionate number of respondents ( 8 each) who used "usually not true" and "always true" as their responses, where each has $16 \%$ of usage. However, differs in terms of cumulative percentage as the former has $26 \%$ while the latter has $100 \%$ which suggest that the conscious use of writing an outline in their paper before start writing an essay in English during UUM English intensive course is more common and dominant as a strategy. The result also presents 5 respondents as the least number of responses and percentage with negative answers (never true) as their claims with $10 \%$ each for valid and cumulative percentage. 


\subsection{Frequency Distribution of Students' responses of Student's Conscious use of writing notes or an outline in native language before start writing an Essay in English}

The result deduced from the WSQ data of this study revealed that 50 EFL international students had responded about their conscious use of writing notes or an outline in their native language before start writing an essay in English during UUM English intensive course and this is shown in Table 4.8 below.

Table 4.8: Frequency Distribution of Students' responses of Conscious use of writing notes or an outline in native language before start writing an essay in English

\begin{tabular}{llcccc}
\hline \multirow{3}{*}{ Valid } & Frequency & Percent & Valid Percent & Cumulative Percent \\
& Never true & 8 & 16.0 & 16.0 & 16.0 \\
& Usually not true & 9 & 18.0 & 18.0 & 34.0 \\
& Somewhat true & 8 & 16.0 & 16.0 & 50.0 \\
& Usually true & 19 & 38.0 & 38.0 & 88.0 \\
Always true & 6 & 12.0 & 12.0 & 100.0 \\
Total & $\mathbf{5 0}$ & $\mathbf{1 0 0 . 0}$ & $\mathbf{1 0 0 . 0}$ & \\
\hline
\end{tabular}

The result of the statistical representation of the frequency distribution of the students' responses shown in above table 4.8, the frequency of the respondents who agreed (usually true) that they write notes or an outline in their native language before start writing an essay in English during UUM English intensive course are far higher than any other item within the 5 items in this scale with 19 respondents and $38 \%$ from the total participants. This is similar with the findings on the frequency of the respondents who agreed that they write an outline in their paper before starts writing an essay in English during UUM English intensive course are far higher than any other item. The only contrast is in cumulative percentage as the former had $88 \%$ while the latter has $84 \%$.

On the other hand, there are a proportionate number of respondents and percentage of EFL students who claimed of conscious use of writing notes or an outline in their native language before start writing an essay in English during UUM English intensive course. From table 4.8, result presents 8 respondents and 16\% each for those who responded with "never true" and those with "somewhat true", however differs in terms of cumulative percentage as the former has $16 \%$ while the latter has $50 \%$ showing a significant difference of disagreement and agreement as answers. This tally with "usually true" responses explained above. The result also presents 9 respondents with $18 \%$ of "usually not true" responses and $38 \%$ cumulative. Meanwhile, the item with the least number of respondents and percentage is "always true" with 6 respondents and 12\% validation at $100 \%$ cumulative.

\subsection{Summary Result of the use of Planning as writing strategy by EFL International students in UUM English Intensive Course}

The detailed means, medians and modes of responses to EFL international students' conscious use of Planning as writing strategy before start writing an essay in English during UUM English intensive course are summarized in Table 4.9.

Table 4.9 indicates that there are 8 different items of planning strategy known as writing planning process (WPP) EFL international students used before they start writing an 
essay in English. According to the Table 4.9, the response "I think about what I want to write and have a plan in my mind, but not on paper" was the most frequent one (WPP5 mean = 3.6000 , sum $=180$ ). This may imply that the majority of students feel that writing does not make them nervous even if they are writing in English. This is followed by the responses "I look at a model written by a native speaker or more proficient writer" (WPP3) and "I write an outline of my paper" (WPP7) with the same mean $=3.3400$. Specifically, this (i.e., WPP3 and WPP7 mean $=3.3400$, sum $=167$ ) shows the students' positive attitude towards writing in English.

Other responses were found at lower degrees of agreement. Meanwhile the least response was "I start writing without having a written or mental plan (WPP4 mean=2.600, Sum $=131$ ). Perhaps this could be the main reason few students normally fail their English essay writing assessment.

Table 4.9: The overall statistics of the extent of the use of planning strategy before start writing an essay in English

\begin{tabular}{|c|c|c|c|c|c|c|c|c|c|}
\hline \multirow{3}{*}{$\mathrm{N}$} & & WPP1 & WPP2 & WPP3 & WPP4 & WPP5 & WPP6 & WPP7 & WPP8 \\
\hline & Valid & 50 & 50 & 50 & 50 & 50 & 50 & 50 & 50 \\
\hline & Missing & 0 & 0 & 0 & 0 & 0 & 0 & 0 & 0 \\
\hline \multicolumn{2}{|c|}{ Mean } & 3.0400 & 3.5600 & 3.3400 & 2.6200 & 3.6000 & 3.5200 & 3.3400 & 3.1200 \\
\hline \multicolumn{2}{|c|}{ Median } & 3.0000 & 4.0000 & 3.5000 & 3.0000 & 4.0000 & 4.0000 & 4.0000 & 3.5000 \\
\hline \multicolumn{2}{|c|}{ Mode } & $2.00^{\mathrm{a}}$ & 4.00 & 4.00 & $2.00^{\mathrm{a}}$ & $3.00^{\mathrm{a}}$ & 4.00 & 4.00 & 4.00 \\
\hline \multicolumn{2}{|c|}{ Sum } & 152.00 & 178.00 & 167.00 & 131.00 & 180.00 & 176.00 & 167.00 & 156.00 \\
\hline
\end{tabular}

a. Multiple modes exist. The smallest value is shown

\section{DISCUSSION}

The central goal of this study was to identify and determine the extent of knowledge awareness of Writing Strategies used by EFL International Students in Universiti Utara Malaysia Intensive English Course. In this attempt, the paper focused on the planning strategies being employed by the students before writing in English.

The likely reasons behind the EFL students' decisions and views are given which may be considered useful and reference for policy makers on education, the English language trainers, administrators and the language researchers among others. With the aid of the responses been generated from the writing strategies questionnaire (WSQ) being adapted from Petric \& Czarl (2003) and the descriptive statistical analysis from SPSS software, this paper revealed an outstanding result derived from the EFL international students' remarkable responses.

In terms of research question: "To what extents are the EFL International Students employ the knowledge awareness of writing strategies in UUM English Intensive Course before writing English Essay?" overall, the study found that EFL students have conscious knowledge of the planning strategies used before start writing in English as recommended by (Flower \& Hayes, 1980; Flower \& Hayes, 1981) which were moderately used during UUM English intensive course and these findings are consistent with the results discovered in Bai et al. (2014) and Mistar et al. (2014). According to Bai et al. (2014), students especially at the Singapore upper primary schools use a wide range of planning writing strategies at a 


\section{Mohammed Ahmad Ado \& Mohammad Othman Ahmad Alsheyab}

medium frequency level. Having similar view, Mistar et al. (2014) claimed that the students normally use planning writing strategies and other methods at the moderate frequency level.

Again, the findings of this paper correspond with that of Raoofi et al. (2014). According to Raoofi et al. (2014) most of the participants had recounted doing some prewriting activities, and were aware of their own writing problems. In addition, the results also show that the highly proficient student writers reported using more metacognitive strategies including organizing ideas and revising content compared with the less skilled ones. However, the Raoofi et al. (2014) used qualitative interview to arrive at the results while this paper used questionnaire approach.

The findings of this paper contradict most of the current related studies the researcher come across in the course of this study (e.g., MacLeod, 2016; Teng \& Zhang, 2018; Nemati et al., 2017) due to differences in research objectives, focus and approaches. For instance; the study of MacLeod (2016) is more into the exploration of the Junior-level English language learners' experiences on academic writing development using qualitative interview. Similarly, Teng \& Zhang (2018) study is not in line with the current paper, as their study revealed the students' having cumulative knowledge of motivational regulation which is an antecedent of the reported use of other SRL strategies that affects EFL writing performance.

Again, the work of Manchón (2018) is more into the nature of L2 writing strategies and her concern was specifically on the potential theoretical and pedagogical lines of inquiry towards the manner in which strategic behavior during writing and during written corrective feedback processing may foster language learning. However, the work of Manchón (2018) triggered the conduct of this paper as she suggested such route could result in interesting and profitable collaborations to incite language learning strategies and recent SLA-oriented L2 writing research initiatives towards language learning potentials associated with L2 writing. In support of this assertion, the findings of this study revealed that most EFL International students did claimed of having the idea of what they want to write in their minds without written outlines. This may imply that the majority of students feel that writing does not make them nervous even if they are writing in English.

On another dimension also, the result of this study to certain extent have equally revealed that there are quite a moderate number of EFL international students who normally look at the model written by a native speakers or more proficient writers and then write their outlines on pieces of paper before start writing in English. This finding corresponds with the suggestion of Maarof \& Murat (2013) who predicted that EFL students are not good at generating ideas, planning or outlining before they start writing. Maarof \& Murat (2013) prediction regarding this issue is also in line with the findings of this paper, although with a very negligible number of EFL students whose views were on starting writing without really having a written or mental plan. Perhaps, this could be the main reason few students normally fail their English essay writing assessment in UUM English intensive course. To this effect the current paper recommends that EFL students in order to improve themselves, they should oblige to adopt the views reflected in Manchón (2018). Accordingly, “.... concepts of writing strategies ought to go beyond individual, solitary acts of writing and be made to encompass strategic behavior in both individual and collaborative writing conditions" (Manchón, 2018). 


\section{LIMITATION}

It is part of the rationale of this paper to acknowledge certain limitations existing in a research of this kind. First and foremost, this paper was strictly focused on EFL international students in UUM English Intensive Course. The data was collected using WSQ which is a method that has certain limitations, even though; the instrument enabled the researcher conveniently extracted data suitable for the research objective. The use of WSQ also enable the researcher to overcome the limitations of other data collection instruments on writing strategies such as think-aloud, videotapes and observations. This also enables participants to be sincere in their responses due to assurance of anonymity of the WSQ and there were no right or wrong answers in the responses. It is also part of the limitation of this paper being that it covers only one of the three writing strategies been formulated and recommended by (Flower \& Hayes, 1980; 1981) and it is limited to only prewriting stage aspect of Petric \& Czarl (2003). The study was also limited to quantitative descriptive statistics and interpretation.

\section{RECOMMENDATION}

In accordance with the limitations of this study, there are quite a number of recommendations:

1. The study of this kind is recommended to be conducted with more than one institution, more sample size of students.

2. Research of this kind should be conducted in future to cover UUM Writing using Translation Strategies.

3. Research is also recommended to be conducted using other methods as think-aloud, video-taping and observation of the attitudes of the student's writing activities.

4. Future research is also recommended to cover Reviewing strategies in the attempt to improve the EFL students' writing performance in English.

5. There is also the possibility of having several variables of cultural influences, background, student's individual personality, style of cognition, motivation, affection, social environment, teaching and learning policies, and beliefs among others that can affect the students writing performance which need to be studied among other issues.

6. Future research of this kind should also be conducted qualitatively in order to expand the portion of this paper. It may also enable the students to share their own views, opinions, experience and the shortcomings regarding the writing strategies in the form of questions and answers which cannot be achieved with questionnaire or quantitative data.

\section{CONCLUSION}

This paper provides a preliminary account of knowledge awareness and planning writing strategies that can be employed for assessment based research. The findings of this paper have also presents the potential of advance research investigations within the scope of EFL writing strategies. The findings of this paper have also provided much insight in the terrain of writing teaching. The level of knowledge awareness and conscious use of writing strategies by EFL International students before writing an essay in English was found and 
determined. Based on the findings of the paper, it was also concluded that there are certain aspects of the planning writing strategy that seem to be neglected due to insufficient attention by EFL students, hence required teachers to pay more attention on introducing these methods in order to make students to be more aware of all the necessary planning writing strategies and improve on their focus and scores.

In addition, recommendations were provided to cover certain limitations discussed in the study such as expanding the scope of the study and increasing the sample size of the subjects. Therefore, the conclusion cannot be generalized. In fact, the study questionnaire was also found to be more or less subjective as viewed by oxford, hence the need to also conduct a qualitative research on this topic in order to use open ended questions so as to supplement the findings of this paper and to confirm the efficiency of the process approach. It may also improve the writing strategies for the teaching English writing in schools of higher learning. The findings of this paper is intended to add value to the existing knowledge of EFL writing strategy research and may also assist both researchers and instructors in gaining much more understanding of the interface between EFL international students and writing strategies.

\section{REFERENCES}

Al-Buainain, H. (2011). Students' Writing Errors in EFL: A Case Study. QNRS Repository, 2011(1).

Al Seyabi, F., \& Tuzlukova, V. (2014). Writing Problems and Strategies: An Investigative Study in the Omani School and University Context. Asian Journal of Social Sciences \& Humanities, 3(4), 37-48.

Alkubaidi, M. A. (2014). The Relationship between Saudi English Major University Students' Writing Performance and Their Learning Style and Strategy Use. English Language Teaching, 7(4), 83-95.

Bai, R., Hu, G., \& Gu, P. Y. (2014). The Relationship between Use of Writing Strategies and English Proficiency in Singapore Primary Schools. The Asia-Pacific Education Researcher, 23(3), 355-365.

Bhatti, M. A., \& Sundram, V. P. K. (2015). Business Research Quantitative and Qualitative Methods. Kuala Lumpur: Pearson Malaysia.

Bjork, L., \& Raisanen, C. (1997). Academic Writing: A University Course. Oxford: Kent.

Cole, J., \& Feng, J. (2015). Effective Strategies for Improving Writing Skills of Elementary English Language Learners. Chinese American Educational Research and Development Association Annual Conference, 2(4), 45-55.

Cresswell, J. (2005). Research Design: Qualitative and Quantitative Approaches. London: Longman.

Crystal, D. (2003). English as a Global Language (2nd ed.). Cambridge: Cambridge University Press.

Cutumisu, M., \& Schwartz, D. L. (2018). The Impact of Critical Feedback Choice on Students' Revision, Performance, Learning, and Memory. Computers in Human 
Behavior, 78, 351-367.

Flower, L., \& Hayes, J. R. (1980). The Dynamic of Composing: Making Plans and Juggling Constraints. In Cognitive Processes in Writing. Hillsdale, NJ: Lawrence Erlbaum Associates.

Flower, L., \& Hayes, J. R. (1981). Identifying the Organization of Writing Processes. In Cognitive Processes in Writing. Hillsdale, NJ: Lawrence Erlbaum Associates.

Hyland, K. (2008). Writing Theories and Writing Pedagogies. Indonesian Journal of English Language Teaching, 4(2), 91-110.

Ibnian, S. (2011). Brainstorming and Essay Writing in EFL Class. Theory and Practice in Language Studies, 1(3), 263-272.

Junqueira, L., \& Payant, C. (2015). I Just Want to Do It Right, but It's So Hard": A Novice Teacher's Written Feedback Beliefs and Practices. Journal of Second Language Writing, 27, 19-36.

Lee, L. F., Sidhu, G. K., Chan, Y. F., Teoh, S. H., Narayanan, G., \& Ishak, M. I. A. M. (2016). Examining Contributory Factors and Barriers to Success in Academic Writing Among Undergraduates. In Regional Conference on Science, Technology and Social Sciences. Singapore: Springer Singapore.

Liu. (2015). Investigating the English Writing Strategies Used by Chinese Senior High School Students. Theory and Practice in Language Studies, 5(4), 844-850.

Maarof, N., \& Murat, M. (2013). Writing Strategies Used by ESL Upper Secondary School Students. International Education Studies, 6(4).

MacLeod, N. M. (2016). Is Anyone Listening? - Experiences of Junior-Level English Language Learners in Southwestern Ontario. University of Windsor.

Manchón, R. M. (2018). Past and Future Research Agendas on Writing Strategies: Conceptualizations, Inquiry Methods, and Research Findings. Studies in Second Language Learning and Teaching, 8(2), 247-267.

Mistar, J., Zuhairi, A., \& Parlindungan, F. (2014). Strategies of Learning English Writing Skill by Indonesian Senior High School Students. Arab World English Journal, 5(1).

Nemati, M., Alavi, S. M., Mohebbi, H., \& Masjedlou, A. P. (2017). Speaking Out on Behalf of the Voiceless Learners: Written Corrective Feedback for English Language Learners in Iran. Issues in Educational Research, 27(4).

Nunan, D. (1992). Research Methods in Language Learning. Cambridge: Cambridge University Press.

Odena, O., \& Burgess, H. (2017). How Doctoral Students and Graduates Describe Facilitating Experiences and Strategies for Their Thesis Writing Learning Process: a Qualitative Approach. Studies in Higher Education, 42(3), 572-590.

Ou, Y. C. A. (2013). Writing Strategies: Perceptions, Experience, and Use in Undergraduate and Graduate ESL Students. Purdue University.

Petric, B., \& Czarl, B. (2003). Validating a Writing Strategy Questionnaire. System, 31, 187215.

Rababah, L., \& Melhem, N. B. (2015). Investigation into Strategies of Creativity in EFL Writing in Jordan. Journal of Literature, Languages and Linguistics, 5, 14-25.

Raoofi, S., Chan, S. H., Mukundan, J., \& Rashid, S. M. (2014). A Qualitative Study into L2 Writing Strategies of University Students. English Language Teaching, 7(11), 39-45. 
Mohammed Ahmad Ado \& Mohammad Othman Ahmad Alsheyab

Ridhuan, M., \& Abdullah, T. L. (2009). The Writing Strategies Used by Engineering ESL Malay Learners. Retrieved February 27, 2017, from http://eprints.utp.edu.my/2035/

Sanavi, R. V., \& Nemati, M. (2014). The Effect of Six Different Corrective Feedback Strategies on Iranian English Language Learners' IELTS Writing Task 2. SAGE Open, 4(2).

Teng, L. S., \& Zhang, L. J. (2018). Effects of Motivational Regulation Strategies on Writing Performance: A Mediation Model of Self-regulated Learning of Writing in English as a Second/Foreign Language. Metacognition and Learning, 13(2), 213-240.

Zhang, Z. (2016). Student Engagement with Computer-generated Feedback: A Case Study. Elt Journal, 71(3), 317-328.

Zhao, H. (2014). Investigating Teacher-Supported Peer Assessment for EFL Writing. ELT Journal, 68(2), 155-168. 